\title{
Low-carbon Scenarios Development for Modal Shift in the Chemical Industry
}

\author{
Barbara Ocicka, ${ }^{1, *}$ \\ ${ }^{1}$ Warsaw School of Economics, Collegium of Business Administration, Department of Logistics, Al. \\ Niepodległości 162, 02-554 Warsaw, Poland
}

\begin{abstract}
Supply chain managers have to deal with the performance requirement to significantly reduce $\mathrm{CO}_{2}$ emissions in searching for excellence in green business processes management. The purpose of this article is to examine the perspectives on low-carbon scenarios development for modal shift in the chemical industry. The author outlines main research findings from the Interreg Central Europe ChemMultimodal project realised by 14 partners from 7 countries, among others by Department of Logistics at Warsaw School of Economics in Poland. The project idea is focused on analysing the potential and growth opportunities for multimodal transport usage in chemical supply chain management. Firstly, the objectives, current status and methodology of the project are explained. Then, the results of the research carried out among chemical and logistics companies operating in Poland are discussed. Furthermore, there is recognised that transport modal shift decisions determine changes in supply chain configurations that might be supported by planning and management tools. Consequently, the elements of the ChemMultimodal toolbox are outlined and its potential significance for low-carbon scenarios development is highlighted. As a result, both theoretical and practical implications of the research findings are indicated.
\end{abstract}

\section{Introduction}

Sustainability is one of the most important sources of competitive advantage of companies and supply chains in today's highly competitive and turbulent global business environment. Consequently, the phenomenon of best practices in logistics and supply chain management has gained strategic importance as a response to the rising problems and challenges, like e.g. limited energy supply, natural resources scarcity or global greenhouse gas (GHG) emissions at an alarming rate. The scope of best practices assessment is based on the necessity of their effects analysis in three categories: economic, social and environmental [1-3]. In this context, much of the recent logistics and supply chain management literature has focused special attention on the sustainability of transport management and operations, addressing especially the question of freight modal shift for greener logistics [4-6].

There is reported, that transport is responsible for 23 per cent of greenhouse gas emissions in the European Union [7]. A lot of initiatives and projects within European

* Corresponding author: barbara.ocicka@sgh.waw.pl 
Union and other countries have taken into account to promote modal shift for decreasing emissions [8]. For instance, the flagship EU initiative is the Trans-European Network (TEN-T) programme, that aims to slow down the rate of increase of $\mathrm{CO}_{2}$ emissions from freight transport operations through a combination of modal shift and more efficient operations [9]. However, there is a wide gap between anticipated real GHG emissions $\left(\mathrm{CO}_{2}\right.$ equivalents) and the ambitious EU purpose to reduce carbon emissions from transportation by 60 per cent by the year 2050 [10]. The just mentioned facts confirm the need to develop green transport practices and the necessity of their dissemination and promotion between companies. Furthermore, a decision support tools and frameworks for companies wanting to reduce their carbon footprint are rightly receiving a great deal of attention [11].

Facing the problem in an European context, there is a need to develop more projects devoted to particular regions and industries, considering their supply chain strategies and configurations. One of the initiatives contributing to the EU macro regional strategies is the Interreg Central Europe programme, that improves significantly capacities for regional development in innovation, $\mathrm{CO}_{2}$ reduction, the protection of natural and cultural resources as well as transport and mobility. One of the initiatives co-funded by the Interreg CE programme is the ChemMultimodal project focused on 2 priorities: to increase multimodal transport by 10 per cent and to reduce $\mathrm{CO}_{2}$ emissions by 5 per cent in the chemical industry.

The purpose of this article is to examine the perspectives on low-carbon scenarios development for modal shift in the chemical industry. It begins with a brief presentation of the ChemMultimodal project objectives, current status and methodology. In the next section, the results of the research carried out among chemical and logistics companies operating in Poland are discussed. Afterwards, the ChemMultimodal toolbox is described and its significance for low-carbon scenarios development is highlighted. Finally, the conclusions and implications of the research, the limitations of the work and recommendations for future research in the field of multimodal transport of chemical goods, are presented.

\section{The ChemMultimodal project objectives and methodology}

The main objective of the ChemMultimodal project is the promotion of multimodal transport of chemical goods by coordination and facilitation of cooperation between chemical companies, specialized logistics service providers (LSPs), terminal operators and public authorities in chemical regions in Central Europe. Its duration is limited to 3 years (from June 2016 till May 2019) and its budget amounts to 2.388.840 Euro. There are 14 project partners engaged from 7 countries: Austria, Czech Republic, Germany, Hungary, Italy, Poland and Slovakia. The specific objectives of the project take into consideration to: improve sustainability of chemical logistics, increase multimodal transport of chemical goods and facilitate cooperation of multimodal stakeholders. The achievement of the just mentioned specific goals should lead to increase multimodal transport by 10 per cent and to reduce $\mathrm{CO}_{2}$ footprint by 5 per cent in the chemical supply chains reached in project lifetime. The ChemMultimodal scope has gained a noticeable significance, because the chemical industry is an important economic sector responsible for 8 per cent of freight transport in European countries.

\subsection{The ChemMultimodal current status}

The scope of the ChemMultimodal project encompasses 4 work packages (Table 1). 
Table 1. ChemMultimodal current status. Source: [12]

\begin{tabular}{|c|cl|}
\hline Work package & \multicolumn{1}{c|}{ WP description } \\
\hline WP1 & $\begin{array}{l}\text { Analysis \& Tool Development } \\
\text { Output: Tool for promotion of modal shift of chemical } \\
\text { goods from road to intermodal transport }\end{array}$ \\
\hline WP2 & - $\begin{array}{l}\text { Pilot Testing } \\
\text { Output: Pilot Projects and implementation in each country }\end{array}$ \\
\hline WP3 & $\begin{array}{l}\text { Capacity Building } \\
\text { Output: 6 Training Seminars (15 participants each) in DE, } \\
\text { AT, HU, PL, IT, SK-CZ }\end{array}$ \\
\hline WP4 & - $\begin{array}{l}\text { Strategy and Action Plan } \\
\text { Output: Transnational Strategy (1) and Action Plans (7) }\end{array}$ \\
\hline
\end{tabular}

The purpose of the first stage of the project (WP1) was to analyse multimodal transport of chemical goods in the countries and regions of project partners, while focusing on identifying multimodal transport importance, main routes, barriers and opportunities to improve the usage of multimodal transport in chemical logistics [13]. The results of the surveys were the starting point to develop the project tool, that should be helpful to promote and increase multimodal transport usage. The second part of work (WP2) is dedicated to pilot testing. The pilot projects will be realized in cooperation with chemical companies and logistics service providers in each country. The engaged entities will switch the so far used road routes to an intermodal road-rail solution. Next, the project partners will analyse and compare the reported data regarding the logistics performance of both transport processes, including: distance, volume, costs, service quality (transit time and punctuality) and $\mathrm{CO}_{2}$ emissions. In consequence, the potential of a shift from road to intermodal road-rail transport, without jeopardizing logistics performance, will be identified. Afterwards, the knowledge generated from the pilot action will be shared and transferred to other companies and LSPs via 6 training seminars. The key purpose of the WP3 is capacity building with engagement of trained companies. Finally, the project team will develop one transnational strategy as well as action plans for each partner country (WP4). The current status of the project is the beginning of the WP2: pilot testing.

\subsection{The ChemMultimodal methodology}

In the WP1, a questionnaire-based survey was carried out among 21 entities between August and September 2016, including 12 chemical companies (producers and distributors) and 9 logistics companies (LSPs, carriers, rail and port operators) operating in Poland. Both groups are very important stakeholders of the ChemMultimodal initiative. The production or distribution companies as shippers make decisions on the purchase of transport and logistics companies play the key role in designing and providing environmentally sustainable solutions for supply chains [14]. Both project partners from Poland - Warsaw School of Economics and Polish Chamber of Chemical Industry were actively engaged.

The WP2 is focused on pilot testing. In this phase, the developed toolbox will be tested throughout the partner regions and countries in 7 pilot projects. Each pilot should work together with at least 5 companies with the objective to test a shift from road to intermodal road-rail transport in supply chains. The chemical and logistics companies engaged in the pilots will fulfil an evaluation questionnaire and report the original and tested routes. As a result, the collected case studies will be analysed to gain knowledge about the potential of 
new supply chain configurations to increase multimodal transport. Each project partner will also organise workshops with companies participating in the pilot stage.

The same methodology of the project throughout the partner regions and countries allows to successfully benchmark and transfer practices, which are worth following nationally and internationally.

\section{Perspectives on multimodal shift in the chemical sector}

The companies surveyed in 2016 evaluated the main advantages of multimodal transport on the scale from 1 - not important to 5 - very important. The outcomes of the evaluation are as follows: cost decrease (4.27), safety in terms of dangerous and hazardous goods transport (4.07), lowering $\mathrm{CO}_{2}$ emission (3.50), time shortening (3.48), supporting CSR strategy (3.34) [13]. The respondents evaluated also the main disadvantages of multimodal transport, among others taking into consideration: lack of railway connections (4.13), lack of intermodal terminals (3.91), transit time (3.88), costs (3.76), low flexibility of transport management (3.64), extended planning and organizing forwarding time (3.31) and sector's regulations (2.46) [13].

In searching for the possibilities to shift road to multimodal transport, the chemical and logistics companies indicated the arguments encouraging them to use and offer multimodal transportation (Table 2). On the demand side, shorter transit time (5.0) and lower costs (4.7) are the main drivers, that could motivate the chemical companies to use multimodal transport. On the supply side, logistics companies may offer more competitive prices in case of large shipments and long-distance transport. The achievement of shorter transit time is more challenging because it depends strongly on external factors, like e.g. lack of direct railway connections or low interoperability within rail transport across Europe [13].

Table 2. Motivation (arguments) for multimodal transport. Source: [13]

\begin{tabular}{|c|c|c|}
\hline $\begin{array}{c}\text { Motivation (arguments) } \\
\text { 1-not important, } \\
\text { 5-very important }\end{array}$ & $\begin{array}{c}\text { AVG. motivation } \\
\text { for chemical companies }\end{array}$ & $\begin{array}{c}\text { AVG. arguments for } \\
\text { logistics companies }\end{array}$ \\
\hline Cost & 4.7 & 5.0 \\
\hline Safety & 3.8 & 4.8 \\
\hline Capacity & 2.8 & 3.8 \\
\hline Mode availability & 3.3 & 3.8 \\
\hline CSR strategy & 2.3 & 3.3 \\
\hline Lowering CO2 emissions & 2.8 & 1.0 \\
\hline Transit time & 5.0 & \\
\hline Sector's regulations & 3.0 & \\
\hline
\end{tabular}

The respondents recognised the modal shift potential in any route characterised as follows: long enough to offer sufficient transport time, offered on a regular and long-term basis, offering backhaul opportunities. The chemical companies are especially interested in the development of the potential multimodal routes between Poland and such countries as: Czech Republic, Germany, Italy, Kazakhstan, Romania, Spain and Turkey.

It should be underlined that the perspectives on multimodal shift in the chemical sector are created by internal and external initiatives and incentives. On the one hand, there is the necessity for closer collaboration between chemical companies or development of sharing services by logistics companies to achieve higher availability of shipment consolidation and better effectiveness of transport solutions. It is also time to change habits of transport planners and enhance sustainability awareness among managers as well as operational workers to manage transport operations in the more environmentally-friendly way and measure key performance indicators in this area. Supply chain and logistics managers may 
use different frameworks and decision supporting tools to improve their practices in multimodal transport management and reduce the companies' carbon footprint [15]. On the other hand, the external incentives to promote multimodal transport are highlighted in the table 3 .

Table 3. External incentives to promote multimodal transport. Source: [16]

\begin{tabular}{|c|c|}
\hline Incentives & Average \\
\hline Improvement of railway connections (frequency and punctuality) & 4.50 \\
\hline Lowering costs of access to multimodal infrastructure & 4.25 \\
\hline Consistency of transport time schedules & 4.25 \\
\hline Better flexibility of transport management & 4.13 \\
\hline Improvement quality of intermodal terminals & 3.75 \\
\hline Increasing number of intermodal terminals & 3.56 \\
\hline Sector's regulations (framework conditions) & 2.50 \\
\hline
\end{tabular}

\section{The ChemMultimodal toolbox and its role in low-carbon scenarios development}

\subsection{Elements of the ChemMultimodal toolbox}

The ChemMultimodal toolbox has been developed in close cooperation with logistics and chemical companies to promote modal shift from unimodal to multimodal chemical goods transport. It consists of four integrated pillars, namely (1) consulting services, (2) planning guidelines, (3) IT Visualization, (4) $\mathrm{CO}_{2}$ Calculator (Fig. 1).

\begin{tabular}{|l|l|}
\hline (1) $\begin{array}{l}\text { Consulting Services } \\
\text { Data base with stakeholders } \\
\text { contacts } \\
\text { Marketing platform }\end{array}$ & \begin{tabular}{l} 
(2) $\begin{array}{l}\text { Planning Guidelines } \\
\text { Backbone of Toolbox } \\
\text { National, legal regulations to } \\
\text { be found here }\end{array}$ \\
\hline (3) Visualization
\end{tabular} \\
$\begin{array}{l}\text { Intermodal Links Platform } \\
\text { Visualize intermodal routes } \\
\text { frequency, available LSPs, } \\
\text { information of pre- and } \\
\text { post-haulage) }\end{array}$ & $\begin{array}{l}\text { CO2 Calculator } \\
\text { Calculation of } \mathrm{CO}_{2} \text { emission } \\
\text { based on EN } 16258 \text { and } \\
\text { McKinnon concept } \\
\text { Create awareness for } \mathrm{CO}_{2} \\
\text { savings }\end{array}$ \\
\hline
\end{tabular}

Fig. 1. Toolbox elements. Source: [12]

The first element called consulting services is focused on the partners' efforts to develop an approach to communicate and discuss the following issues with representatives of chemical and logistics companies: current transport patterns, existing potentials and possible actions to encourage modal shift and promote multimodal solutions. The second element known as planning guidelines is a backbone of the toolbox, because it provides national transport regulations, including e.g. loading and driving restrictions. The third element is a practical IT visualization established as an Intermodal Links Platform. It plays the role of the planner, that enables to visualize intermodal routes according to the requirements of the user, to present the list of available transportation offers of LSPs (including main, pre- and post-haulage routes) and contacts details. The fourth element is 
the $\mathrm{CO}_{2}$ calculator, which gives useful feedback on $\mathrm{CO}_{2}$ emissions with regards to different transport scenarios and helps in choosing the most environmentally-friendly option (Fig. 2).

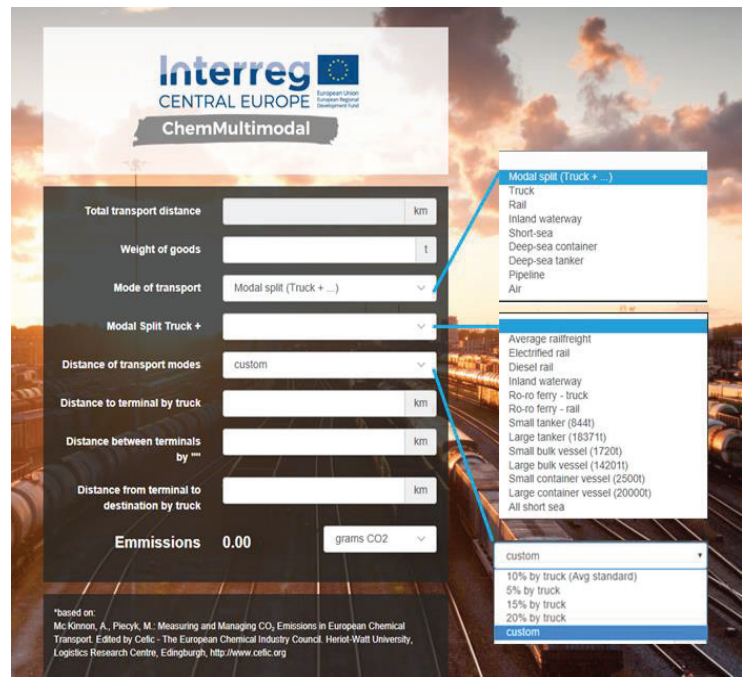

Fig. 2. $\mathrm{CO} 2$ Calculator for chemical transports. Source: [17]

It should be kept in mind that consulting services provide sufficient knowledge about the demand and needs of the chemical companies and LSPs using the three other elements (Fig. 3).

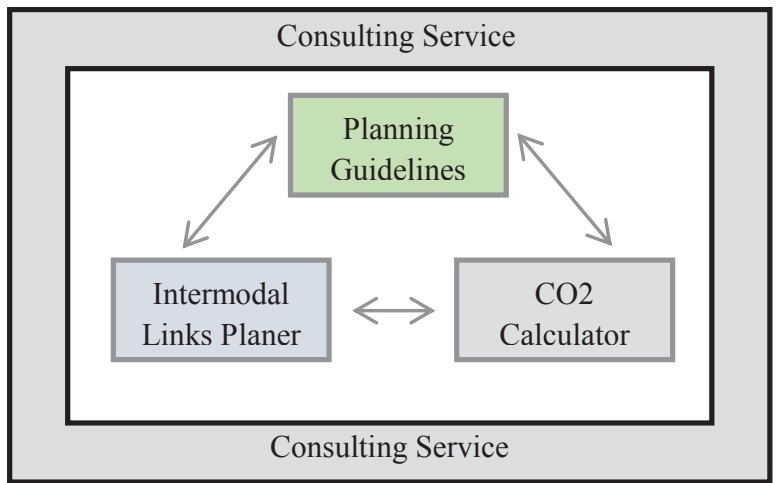

Fig. 3. Links between the toolbox elements. Source: [12]

\subsection{Significance of the toolbox}

The toolbox has a potential of a control tower for multimodal transportation planning and management, that supports chemical companies and LSPs in strategic and operational-level issues. The key purpose of its development and continuous improvement is to contribute significantly to optimization of the utilisation of multimodal transport solutions in the chemical industry. The Intermodal Links Platform creates a lot of cooperation possibilities between chemical companies and LSPs, accordingly on demand and supply side. There is not only the possibility to offer and buy full loads services. The planner offers as well the possibility to share transport vehicles and combine loadings ensuring the achievement of the highest possible filling rates and transport costs reductions. It allows in the best possible 
way, that every shipment in Europe might be planned and executed in a multimodal manner, including road service only for short pre-haulage and post-haulage distances to or from the transhipment terminals. According to shipper perspectives, the ChemMultimodal toolbox is useful on the most of the levels of low-carbon scenarios development in transport management.

\section{Conclusion and future research}

In summarizing the research findings in the ChemMultimodal project, switching to an intermodal road-rail solution is potentially worth considering, in particular, because of costs and safety reasons, but difficult to implement as it may jeopardize logistics performance with regards to transit time or flexibility. However, the strong need for low-carbon scenarios development in supply chain management requires to plan and manage modal shift in different industries. Logistics and supply chain managers need concepts and tools supporting and encouraging them to a change from unimodal truck to multimodal transport. The ChemMultimodal project delivers the toolbox, that allows to plan various multimodal scenarios and measure $\mathrm{CO}_{2}$ emission as an indicator of environmental performance. It will be tested and further developed by the use of empirical data. In searching for low-carbon scenarios in the chemical industry, the future research will be focused on the empirical analysis of case studies of companies that will conduct modal shift in supply chains and verify its economic and environmental effects. This study has without a doubt several limitations, like: concentration on the single industry, limited number of pilots testing the scenarios for modal shift and difficult benchmarking analysis.

The article is a result of ChemMultimodal Project implementation and is co-financed by Interreg Central Europe Programme.

\section{EITEO CENTRAL EUROPE ChemMultimodal}

Scientific work financed from funding for science in the years 2016-2019 granted for the implementation of the co-financed international project.

This paper is supported by the research project "From horse-drawn railway to intermodal transport" within Visegrad Fund.

\section{References}

1. J. Elkington, Cannibals with Forks: The Triple Bottom Line of the $21^{\text {st }}$ Century Business (Capstone Publishing, 1999)

2. C.R. Carter, D. S. Rogers, IJPDLM 38, 360-387 (2008)

3. K. Rutkowski, Best Practices in Logistics and Supply Chain Management. The Case of Poland (OW SGH, Warsaw, Poland, 2009)

4. F. Eng-Larsson, Ch. Kohn, IJPDLM 42, 36-59 (2012)

5. H. Pålsson, O. Johansson, Benchmarking: An International Journal 23, 674-703 (2016) 
6. H.A. von der Gracht, I. L. Darkow, IJLM 27, 142-166 (2016)

7. European Commission, A European Strategy for Low-Emission Mobility (Brussels, Belgium, 2016)

8. R. Konings, H. Priemus, P. Nijkamp, The Future of Intermodal Freight Transport. Operations, Design and Policy (Edward Elgar Publishing, Cheltenham, UK, 2008)

9. A. McKinnon, M. Browne, A. Whiteing, M. Piecyk, Green Logistics: Improving the Environmental Sustainability of Logistics (Kogan Page, London, UK, 2015)

10. European Commission, Roadmap to single European transport area - towards a competitive and resource efficient transport system (Brussels, Belgium, 2011)

11. K. Liljestrand, M. Christopher, D. Andersson, IJLM 26, 296-312 (2015)

12. N. Moritz, Status quo. Toolbox. Future steps (2017)

13. M. Cichosz, K. Nowicka, A. Pluta-Zaremba, M. Susik, Report on analysis of multimodal transport of chemical goods for the identification of modal shift (2016)

14. A. Bask, M. Rajahonka, IJPDLM 47, 560-602 (2017)

15. M. Cichosz, K. Nowicka, Narzędzia wsparcia zarządzania transportem multimodalnym - Projekt ChemMultimodal (2017)

16. M. Cichosz, K. Nowicka, A. Pluta-Zaremba, Przemysł Chemiczny 7, 1435-1439 (2017)

17. Interreg Central Europe, $\mathrm{CO} 2$ Calculator for Chemical Transports, Available online: https://ifsl50.mb.uni-magdeburg.de/chemmultimodal/ (2017) 